\title{
EL CONSUMO EN EL PENSAMIENTO ILUSTRADO ESPAÑOL
}

\author{
Francisco Feo Parrondo \\ Departamento de Geografía \\ Universidad Autónoma de Madrid
}

\section{RESUMEN}

Se analizan las valoraciones que algunos de los principales ilustrados españoles (Feijoo, Jovellanos, Campomanes, Floridablanca, Cadalso, Arriquizar, Florez Estrada y Canga Argüelles) hicieron sobre el consumo desde tres perspectivas complementarias: social, económica y geográfica.

Palabras claves: consumo, moda, desigualdad social, comercio

\section{SUMMARY}

This is an analysis of some of the ilustrated spanish mins (Feijoo, Jovellanos, Campomanes, Floridablanca, Cadalso, Arriquizar, Florez Estrada y Canga Argüelles) evaluation of consumption from three complementary perspectives: social, economic and geographic.

Key words: consumption, fashion, social inequality, trade.

\section{Introducción}

«Todos los hombres serían iguales si no tuvieran necesidades»

(VOLTAIRE)

"Todo hombre es rico o pobre según el grado en que pueda gozar de las cosas necesarias, convenientes y gratas de la vida»

(ADAM SMITH)

Estas dos referencias de grandes pensadores del XVIII nos sirven de punto de partida para reflexionar sobre la concepción que los ilustrados tenían sobre el consumo, objeto del 
presente artículo. Varios problemas metodológicos y conceptuales se nos plantean al intentar abordar este tema. En primer lugar, la propia definición de «ilustrados» (cada autor da una diferente) y su delimitación temporal, que varía sustancialmente de unos estudiosos a otros y, sobre todo, en función del país analizado. Por ejemplo, para Antonio Mestre, «La Ilustración abarcaría el movimiento cultural aproximadamente de 1680 a 1780, pues la Revolución y los cambios mentales y sociales subsiguientes darían paso a una nueva etapa histórica» (MESTRE SANCHIS, 1993, pp. 9). En cambio, J.C. Enriquez hace referencia al absolutismo ilustrado y primer romanticismo burgués, sin separarlos para el periodo 17661833 (ENRÍQUEZ FERNÁNDEZ, 1994a, pp. 11). Por su parte, Lluís Argemí apunta que «tanto por la existencia de precursores, como por el hecho que el pánico a la Revolución Francesa y los avatares políticos posteriores retrasaron la culminación hasta bien entrado el siglo XIX, partiremos de la idea de que la ilustración en nuestro país comenzó con Feijoo y acabó en el trienio liberal» (ARGEMI, 1988, pp. 14). Martínez Cachero apunta la existencia de cuatro generaciones de ilustrados españoles: la de 1714 que, con José de Campillo y Cosío, inicia el camino crítico de la sociedad y la cultura; la de Feijoo que consolida estos enfoques; la de Campomanes que accedió al poder con Carlos III; y la de Jovellanos, de enfoque más liberal, que prepara el fin del Antiguo Régimen (MARTÍNEZ CACHERO, 1976, pp. 16-17). Dado que llevábamos cierto retraso con respecto a otros países europeos, decidimos que el ámbito temporal del estudio incluya el primer tercio del siglo XIX para poder incorporar las aportaciones de Florez Estrada y Canga Argüelles. Sin pretender la exhaustividad de temas ni autores, los hemos agrupado en tres enfoques: social, económico y geográfico.

\section{Enfoque social del consumo}

Benito Jerónimo Feijoo nos aporta dos reflexiones de enfoque social sobre el consumo: su visión de las modas y de las limitaciones al consumo durante la Cuaresma.

Sobre las modas, trata de desmitificarlas desde el principio cuando escribe que el mundo siempre se inclina hacia nuevos usos y que «piensan algunos que la variación de las modas depende de que sucesivamente se va refinando más el gusto, o la inventiva de los hombres cada día es más delicada. Notable engaño! No agrada la moda nueva por mejor, sino por nueva. Aún dije demasiado. No agrada porque es nueva, sino porque se juzga que lo es, y por lo común se juzga mal. Los modos de vestir de hoy, que llamamos nuevos, por la mayor parte son antiquísimos. Aquel linaje de anticuarios, que llaman medallistas (estudio que en las naciones también es de la moda), han hallado en las medallas, que las antiguas emperatrices tenían los mismos modos de vestidos y tocados que, como novísimos, usan las damas en estos tiempos» (FEIJOO, 1952, pp. 66-67).

Aún reconociendo las constantes modificaciones de la moda a lo largo de la historia, Feijoo critica el acelerón de estos cambios en el siglo XVIII hasta el extremo de arrinconar ropa apenas usada y actuar de un modo irracional: «Antes el gusto mandaba en la moda, ahora la moda manda en el gusto. Ya no se deja un modo de vestir porque fastidia, ni porque el nuevo parece, o más conveniente o más airoso. Aunque aquel sea y parezca mejor, se deja porque así lo manda la moda. Antes se atendía a la mejoría, aunque fuese sólo imaginada, o por lo menos un nuevo uso, por ser nuevo, agradaba, y hecho agradable, se admitía; ahora, aún cuando no agrade, se admite sólo por ser nuevo. Malo sería que fuese tan inconstante el gusto; pero peor es que sin interesarse el gusto haya tanta inconstancia» (FEIJOO, 1952, pp. 67). Sobre la vigencia actual del texto sobran los comentarios.

Estos cambios de moda fueron propiciados primero en París, luego en el resto de Francia, y posteriormente en el resto de Europa. Feijoo apunta que es un buen negocio para 
Francia, que por esta vía exporta productos abundantes hacia otras cortes europeas, hace cambiar el buen gusto por la extravagancia, etc., crítica que acompaña con una nítida valoración: «casi todas las modas nuevas me dan en rostro, exceptuando aquellas que, o cercenan gasto, o añaden decencia» (FEIJOO, 1952, pp. 68).

Feijoo señala que las mujeres aceptan el «martirio» de la moda en muchos aspectos: opresión del cuerpo, manos que no se pueden apenas mover, etc. Cuando su entorno acepta una moda esta se queda desfasada sin que haya sido valorado su atractivo salvo porque venga de París. Se muestra sarcástico al comentar alguna moda específica: «Yo me figuro que en aquel tiempo que las damas empezaron a emblanquecer el pelo con polvos, todas hacían representación de viejas. Se me hace muy verosímil que alguna vieja de mucha autoridad inventó aquella moda para ocultar su edad, pues pareciendo todas canas, no se distingue en quien es natural o artificial la blancura del cabello» (FEIJOO, 1952, pp. 68).

La visión que Feijoo tenía de la moda era bastante amplia ya que afectaba a muchos ámbitos de la vida: "Aún fuera tolerable la moda si se contuviese en las cosas que pertenecen al adorno exterior; pero esta señora ha mucho tiempo que salió de estas márgenes, y a todo ha extendido su imperio. Es moda andar de esta o aquella manera, tener el cuerpo en esta o aquella positura, comer así o asado, hablar alto o bajo, usar estas o aquellas voces, tomar el chocolate frío o caliente, hacer esta o aquella materia de la conversación. Hasta el aplicarse a adquirir el conocimiento de esta o aquella materia se ha hecho cosa de moda» (FEIJOO, 1952, pp. 68).

Los peligros para la salud de algunas modas o hábitos de consumo tampoco son una novedad actual ya que Feijoo los apunta muy claramente: «los años pasados eran de la moda las mujeres descoloridas, y que algunas, por no faltar a la moda, o por otro peor fin, a fuerza de sangrías se despojaban de sus nativos colores (...) Y también era desdicha que los hombres hiciesen veneno de la triaca, malogrando en estragos de la vida el color pálido» (FEIJOO, 1952, pp. 69). Estos hábitos le llevan a afirmar que «la mayor tiranía de la moda es haberse introducido en la naturaleza», aunque luego ve más fuera de lugar los cambios en las oraciones de moda, libros y ejercicios espirituales e invocaciones a santos de moda, etc., por lo que escribe que «en nada parece que es tan irracional la moda, o la mudanza de moda, como en materias de virtud». Para Feijoo, «la razón de la utilidad debe ser la regla de la moda» como en cualquier otro tema y propone una vía intermedia: tan irracional es aborrecer todas las modas como abrazarlas todas, debiendo acogerse las útiles y honestas y rechazarse las que no traigan otra recomendación que la novedad o las inmorales como el uso de afeites por los hombres y las escandalosas usadas por las mujeres.

Bajo el título «La Cuaresma salutífera», Feijoo revisa las numerosas exenciones avaladas por los médicos para comer carne en dicho periodo, inclinándose preferentemente por los enfoques médicos frente a los religiosos para señalar que los pescados, frutas y legumbres son más adecuados que las carnes para prevenir y curar enfermedades ${ }^{1}$, aunque los médicos deban tener en cuenta los gustos alimenticios de los enfermos. Si alguno de los alimentos cuaresmales no son adecuados a determinados pacientes, Feijoo recomienda que se corrijan con un condimento oportuno, se palíen con un poco más de vino en la dieta o se sustituyan por otros productos. Para Feijoo, los médicos deberían reflexionar más antes de excusar la abstinencia cuaresmal a cualquier enfermo y, especialmente a los ricos, porque éstos «pueden, entre muchos alimentos cuaresmales, escoger los más cómodos respectivamente a su complexión. Pueden asimismo corregir los que son incómodos, ya con la bebida conveniente, ya con el condimento oportuno. Los pobres están, por lo común, precisados a

1 Feijoo concluye, sin embargo, inclinándose por una dieta variada a lo largo del año a la que considera la más sana y perfectamente compatible con la abstinencia cuaresmal. 
unas berzas de mala calidad y mal o nada aderezadas; cuando más, a un pescado muy salado o medio podrido. Sobre esto su bebida ordinaria, por lo menos en los países donde el vino es género extranjero y costoso, es agua. A todo se añade, que los pobres (no hablo aquí de los que mendigan de puerta en puerta, sino de labradores y oficiales de la más humilde clase en materia de conveniencias) no exageran sus indisposiciones, como los ricos, y apenas acuden jamás al médico, ni quieren ser tratados como enfermos, sin mucho motivo. Por todas estas razones los médicos deben ser incomparablemente más fáciles en excusar de la abstinencia cuaresmal a los pobres que a los ricos. No sé si algunos lo hacen al revés. Por lo menos es cierto que, a proporción, son muchos más los ricos que comen carne en cuaresma, que los pobres» (FEIJOO, 1952, pp. 387).

También Pedro Rodríguez Campomanes (1723-1802) nos aporta algunas ideas sobre su concepción social del consumo. En su «Bosquejo de política económica española», escrita hacia 1750, apunta: «No es mi ánimo proponer aquí la igualdad de bienes de todos los individuos; éste sería un proyecto inasequible mientras dure el género humano, pues aún dada la igual distribución, en breve la codicia, afán o aplicación de los laboriosos se apropiaría los distribuídos a los flojos, perezosos y gastadores (...). Pretendo, sí, únicamente evitar aquella suma desigualdad que hace a la mayor parte de los vasallos unos míseros colonos y es uno de los motivos de la despoblación de España y aridez de sus campos» (RODRÍGUEZ CAMPOMANES, 1984, pp. 64-65).

Un cuarto de siglo después, Campomanes publica su «Discurso sobre la educación popular de los artesanos y su fomento» en el que mezcla un enfoque práctico, destinado a los artesanos y los gremios de las principales localidades, y otro moralista, muy util desde una perspectiva del consumo. Para Campomanes, en la educación de los artesanos debía darse un mayor aseo en ellos y en su vestimenta, al tiempo que deberían dejar de usar capa en el vestido: «harían pues muy bien los padres y maestros en no dar a los muchachos capa, vistiéndolos de las ropas cortas y ajustadas, que son más baratas porque llevan menos tela y forro, y son más acomodadas para los que se dedican al trabajo» (RODRÍGUEZ CAMPOMANES, 1978, pp. 101).

Este enfoque moralista se hace más patente y crítico cuando analiza las ocupaciones del tiempo de ocio de los artesanos: «El abuso de entrar en la taberna la gente oficiala, los encamina a la embriaguez y al juego de naipes en la misma taberna. Entregados los aprendices, y oficiales a estos dos vicios, trabajan de mala gana en los días que no son de precepto; y consumen en el de fiesta lo que debían guardar para mantenerse entre semana y reponer sus vestidos» (RODRÍGUEZ CAMPOMANES, 1978, pp. 101). Para evitar esto, propone que los taberneros sólo vendan el vino en vasija o jarro para que se consuma en casa y que no lo hagan de fiado: las tabernas serían meras tiendas de vino vendible al contado y con la prohibición de beber. Lo mismo debería hacerse con las aguardenterías y otras oficinas expuestas a los mismos vicios que las tabernas. Trata de reducir los vicios de consumo mediante una mezcla de educación adecuada para los niños y leyes restrictivas para los adultos, al tiempo que expresa su creencia de que el tiempo de ocio debe reducirse. Las diversiones deben ser en festivos y nunca en días laborales, apuntando como modelo las corridas de toros de Cádiz y Lisboa en las tardes de los festivos. También critica que muchos extiendan las fiestas a los lunes ya que «tales desórdenes no se oponen solamente a las leyes civiles, sino también a los preceptos de la religión, que no permiten gastos exorbitantes en perjuicio de la propia familia; ni la disipación del caudal, que los padres deben reservar a sus hijos, dándoles buen ejemplo» (RODRÍGUEZ CAMPOMANES, 1978, pp. 134)².

2 Una revisión amplia del papel del catolicismo en la evolución del consumo en España puede verse en Alonso y Conde, quienes atribuyen al protestantismo un papel fundamental en la producción y al catolicismo en el consumo, al contrario de otras teorías precedentes (ALONSO y CONDE, 1994, pp. 38 y ss.). 
Campomanes jugó un papel decisivo en la línea educativa de la Sociedad Económica Matritense, indicador del modelo educativo ilustrado: «las finalidades de las escuelas de la Matritense eran, sustancialmente, tres: la formación moral y religiosa, la finalidad propiamente ilustrada de consecución de la felicidad y el bienestar individual y colectivo y la formación técnica y económica. Es difícil establecer un orden de prioridades entre dichas finalidades, por lo que hay que considerarlas complementarias e interrelacionadas entre sí» (NEGRIN, 1984, pp. 29).

Sobre las constantes variaciones de actividades y consumo se plantea: «¿Qué sabemos, si las pelucas durarán por muchos siglos, y si los peinados de las mujeres harán la ocupación de jóvenes robustos, que estarían más bien empleados en la labranza o en el ejército? Así sucederá cuando caigan en cuenta las gentes, de que es destino propio de las criadas. Su ociosidad gravemente perjudicial, no debe sostenerse con tanta pérdida de hombres: éstos serían más útiles viviendo dedicados a otros oficios, y apartados de una indecente afeminación»(RODRÍGUEZ CAMPOMANES, 1978, pp. 162). Esta visión sexista del trabajo no le impide mostrarse partidario de la incorporación de la mujer a determinados sectores productivos: «las mujeres deberían ocuparse en muchos oficios que emplean hombres. Esa mayor ventaja sacaría el Estado de un sexo cuyos individuos viven en gran parte sin modo de ganar recogidamente el sustento. Tal es el bordado; muchos géneros de tejidos; algunos ramos de la sastrería, y otras varias cosas, para que tienen mayor disposición que los hombres y más facilidad de aprenderlas: a que debe agregarse la preparación de muchas primeras materias. En una palabra las artes sedentarias, en que no es necesario gran esfuerzo corporal, y piden aseo; tal vez son las más a propósito las mujeres» (RODRÍGUEZ CAMPOMANES, 1978, pp. 183). La incorporación de la mujer a estas tareas reduciría costes al tener un jornal incomparablemente menor que los maestros y oficiales y ahorraría muchas compras «que ella sabrá hacer fácilmente con muy poca tarea» (RODRÍGUEZ CAMPOMANES, 1978, pp. 183).

Campomanes opina también sobre el consumo de artículos de lujo, mostrándose partidario de que se prohiba su importación para beneficiar la producción propia. No se debía prohibir la producción ni el consumo de estos artículos sino exclusivamente su importación (RODRÍGUEZ CAMPOMANES, 1978, pp. 198), lo que parece una contradicción con sus propuestas de libre comercio sobre las que luego volveremos.

Muy sugerentes son también las «Cartas Marruecas» escritas por José Cadalso (17411782) hacia 1773-74. En ellas se reflejan los cambios de hábitos de consumo en distintas culturas y especialmente en España y Europa. La carta II señala que los europeos se han uniformado en mesas, teatros y paseos, ejército y lujo pero siguen siendo diferentes en leyes, vicios, virtudes y gobiernos (CADALSO, 1992, pp. 11). En la carta IV apunta que, a lo largo del siglo XVIII, se ha ido despojando de la austeridad y rigor de los pasados, las cortes tienden a uniformarse en el lujo y algunos empiezan a ver la felicidad en que se comía con más primor. En la XI define al aristócrata como aquel que come al año por valor de 200 pesos pero gasta en comida 100.000 en invitar a otros (CADALSO, 1992, pp. 42).

La carta XLI, supuestamente firmada por el marroquí Gazel, es la más interesante para analizar las diferencias culturales y la opinión de Cadalso sobre el lujo. El marroquí escribe: «nosotros nos vestimos como se vestían dos mil años ha nuestros predecesores; los muebles de las casas son de la misma antigüedad de los vestidos; la misma facha tienen nuestras mesas, trajes de criados y todo lo restante; por todo lo cual sería imposible explicarse el sentido de esta voz: lujo. Pero en Europa, donde los vestidos se arriman antes de ser viejos, y donde los artesanos más viles de la república son los legisladores más respetados, esta voz es muy común»(CADALSO, 1992, pp. 88). Define lujo como la abundancia y variedad de cosas superfluas a la vida y señala que era defendido por los 
países que creaban nuevos productos fruto de su ingenio inventivo, de su industria mecánica que producía más que la demanda. La propuesta de Cadalso queda muy clara: «Fomente cada pueblo el lujo que resulta de su mismo país, y a ninguno será dañoso. No hay país que no tenga alguno o algunos frutos capaces de adelantamiento y alteración. De estas modificaciones nace la variedad; con ésta se convida la vanidad; ésta fomenta la industria, y de esto resulta el lujo ventajoso al pueblo, pues logra su verdadero objeto, que es el que el dinero físico de los ricos y poderosos no se estanque en sus cofres, sino que se derrame entre los artesanos y pobres»(CADALSO, 1992, pp. 88).

La compra de cadenas de reloj, vueltas de encaje, palilleros, abanicos, cintas y aguas de olor suponen el empobrecimiento de España, que tiene que exportar oro y plata ante la ausencia de estas fábricas en territorio español. Para Cadalso sólo había dos soluciones: crear estas industrias o privarse de su consumo sustituyendo estos productos por un «lujo nacional que igualmente lisonjeará el orgullo de los poderosos, y les obligaría a hacer a los pobres partícipes de sus caudales» (CADALSO, 1992, pp. 89). Cadalso comparte con Campomanes la idea de reducir importaciones pero es más pesimista ya que considera que es muy difícil competir en precio y calidad con las empresas extranjeras: «lo de afuera siempre tendrá más despacho, porque el comprador acude siempre a donde por el mismo dinero halla más ventaja en la cantidad y calidad, o ambas» (CADALSO, 1992, pp. 90). En caso de competencia, las empresas extranjeras, con más recursos acumulados, rebajarían los precios unos años para eliminarla. También era difícil inventar un «lujo nacional» porque hacía mucho tiempo que reinaba la epidemia de la imitación ${ }^{3}$.

Según Cadalso, se había pasado de un lujo español en el siglo XVI a uno de importación en el XVIII. La descripción que hace de un día en la vida de un acaudalado nos muestra perfectamente ese lujo de importación: «Despiértanle dos ayudas de cámara primorosamente peinados y vestidos; toma café de Moca exquisito en taza traída de la China por Londres; pónese una camisa finísima de Holanda, luego una bata de mucho gusto tejida en León de Francia; lee un libro encuadernado en París; viste a la dirección de un sastre y peluquero francés; sale con un coche que se ha pintado donde el libro se encuadernó; va a comer, en vajilla labrada en París o Londres, las viandas calientes, y en platos de Sajonia o China las frutas y dulces; paga a un maestro de música y otro de baile, ambos extranjeros; asiste a una ópera italiana, bien o mal representada, o a una tragedia francesa, bien o mal traducida; y al tiempo de acostarse, puede decir esta oración: «Doy gracias al cielo de que todas mis operaciones de hoy han sido dirigidas a echar fuera de mi patria cuanto oro y plata ha estado en mi poder»» (CADALSO, 1992, pp. 91).

Junto a esta crítica lectura social de las costumbres hace una más moralista al señalar que «todo lujo es dañoso porque multiplica las necesidades de la vida, emplea el entendimiento humano en cosas frívolas y, hermoseando los vicios, hace despreciable la virtud, siendo ésta la única que produce los verdaderos bienes y gustos» (CADALSO, 1992, pp. 92).

En la carta LXXXV, Cadalso critica no sólo el modo de vida de la corte y grandes ciudades sino también el de las villas y aldeas: «son muchos millares de hombres los que se levantan muy tarde, toman chocolate muy caliente, agua muy fría, se visten, salen a la plaza, dan cuatro paseos, se informan en qué estado se hallan los chismes y hablillas del lugar, vuelven a casa, comen muy despacio, duermen la siesta, se levantan, dan un paseo al campo, vuelven a casa, se refrescan, van a la tertulia, juegan a la malilla, vuelta a casa, rezan el rosario, cenan y se meten en la cama»(CADALSO, 1992, pp. 176).

3 A lo largo de la obra, Cadalso reincide frecuentemente en este tema. Por ejemplo, en la carta XXXV, critica la introducción de vocablos franceses, mudanza que atribuye a los caprichos de sastres, zapateros, ayudas de cámara, reposteros, cocineros, peluqueros, etc. (CADALSO, 1992, pp. 82). 
En la carta LXXXVIII, vuelve a atacar durísimamente el lujo contra el que señala que no hay remedios para prevenir sus daños ya que «tiene demasiado atractivo para dar lugar a otra cualquiera persuasión; y así, los que nacen en semejantes eras se cansan en balde si pretenden contrarrestar la fuerza de tan furioso torrente. Un pueblo acostumbrado a delicadas mesas, blandos lechos, ropas finas, modales afeminados, conversaciones amorosas, pasatiempos frívolos, estudios dirigidos a refinar las delicias o lo restante del lujo, no es capaz de oír la voz de los que quieran demostrarle lo próximo de su ruina. Ha de precipitarse en ella como el río en el mar. Ni las leyes suntuarias, ni las ideas militares, ni los trabajos públicos, ni las guerras, ni las conquistas, ni el ejemplo de un soberano parco, austero y sobrio, bastan a resarcir el daño que se introdujo insensiblemente» (CADALSO, 1992, pp. 180). La alta valoración de cualquier cambio la deja muy clara: «la invención de un sorbete, de un peinado, de un vestido y de un baile, es tenido por prueba matemática de los progresos del entendimiento humano» (CADALSO, 1992, pp. 181).

\section{El consumo en el sistema económico}

Las principales aportaciones de los ilustrados españoles al conocimiento del consumo tienen un enfoque económico, también dominante entre los ilustrados franceses, británicos, etc.

El francés Quesnay es, tal vez, quien mejor sintetiza el enfoque económico del consumo por los ilustrados europeos. Quesnay señala como el tradicional comercio de productos básicos estaba casi paralizado en Francia mientras crecía notablemente el de artículos de lujo, lo que suponía cambios profundos en el consumo y en la economía gala, aumentando las exportaciones, pero «el consumo mantenido por el lujo es demasiado limitado, no puede sostenerse más que por la opulencia, y los hombres poco favorecidos por la fortuna no pueden entregarse a ella más que con perjuicio suyo y desventaja para el Estado. El ministerio más ilustrado sabe que el consumo que puede proporcionar al soberano grandes rentas y que hace la felicidad de sus súbditos es ese consumo general que satisface las necesidades de la vida» (QUESNAY en MESTRE SANCHIS, 1993, pp. 181-182).

Quesnay integra el consumo en el sistema productivo de manera muy clara: «son los grandes ingresos lo que da lugar a grandes gastos, y son los grandes gastos lo que aumenta la población, pues éstos extienden el comercio y los trabajos y proporcionan retribuciones a gran número de hombres(...). Las ventajas más esenciales que resultan de una gran población son los productos y el consumo, que aumentan y ponen en movimiento las riquezas pecuniarias del reino»(QUESNAY en MESTRE SANCHIS, 1993, pp. 183). Estas teorías tratará de rebatirlas Malthus en el «Primer ensayo sobre la población» (1798) al señalar que la población crece más rápidamente que la producción de alimentos.

Quesnay parece inclinarse de manera clara por la potenciación de una sociedad de consumo de masas como reactivadora de la actividad económica: «los productos no pueden, pues, ser riqueza para ninguna nación más que mediante la abundancia y mediante el buen precio, constantemente mantenido a través de un buen cultivo, un gran consumo y un comercio exterior» (QUESNAY en MESTRE SANCHIS, 1993, pp. 184).

Estos pensamientos de Quesnay aparecen reflejados en la «Recreación Política» publicada en 1779 por el ilustrado vasco Nicolás de Arriquizar (1714-1775), quien deja claro que se debe tener en cuenta todo el ciclo económico, de la producción al consumo, ya que cada fase repercutirá positiva o negativamente en las restantes: mayor población implicará más producción, transformación, comercio y consumo y éste, a su vez, aumentará los efectivos demográficos para reiniciar el círculo de nuevo. Para Enriquez Fernández, Arriquibar «fetichiza el número de los hombres y, en consecuencia, sublima los consumos y las 
mercancías» ya que «la concurrencia en el mercado no viene determinada por las necesidades de una población creciente o de unos consumos necesarios» (ENRÍQUEZ FERNÁNDEZ, 1994b, pp. 35).

Nicolás de Arriquibar se inclina por la Unica Contribución como sustituta de las caóticas rentas provinciales ya que los múltiples y crecidos derechos que se cobraban sobre los comestibles eran el mayor obstáculo para el desarrollo: el libre comercio de granos era una necesidad social. Con ciertos matices también lo defiende unas décadas después Valentín de Foronda (1751-1821) al considerarlo básico para la mejora industrial y el incremento demográfico: «el comercio nos trae lo necesario y se lleva lo superfluo». Foronda va más allá en sus propuestas liberalizadoras: arremete contra las alcabalas que dificultan la venta de bienes y la circulación de mercancías, «ataca los impuestos sobre los consumos, la contribución única, el diezmo eclesiástico y propone un sistema fiscal impositivo basado exclusivamente en la contribución personal» (ENRÍQUEZ FERNÁNDEZ, 1994b, pp. 57). Estas propuestas de Foronda van bastante más allá de las de los ilustrados «clásicos» como Campomanes, Jovellanos, etc.

En 1762, Campomanes publica sus «Reflexiones sobre el comercio español a Indias», clave para acercarnos a su visión del comercio y del consumo. Desde sus inicios deja muy clara su postura: «la fuerza de una monarquía consiste en su población y en su comercio. Para conseguir uno y otro es necesario hacer florecer la agricultura, las artes y la navegación. Esta última facilita el transporte de los frutos y de las manufacturas, que son el producto de la agricultura y de las artes. Toda la decadencia de nuestros labradores y artesanos consiste en no tener despacho sus frutos ni sus manufacturas» (RODRÍGUEZ CAMPOMANES, 1988, pp. 3).

Para Campomanes, el problema no es la falta de posibles compradores en América sino el monopolio de exportación por el puerto de Cádiz, motivo por el que pide a Carlos III que lo liberalice: «Cierto es que desde Cádiz no se puede hacer todo el comercio de América, porque un puerto solo no es capaz de abastecer tan inmensos países, ni hay nación sino la española que haya emprendido un método semejante de comercio. Inglaterra, Holanda, Dinamarca y Francia permiten la navegación a sus colonias desde todos los puertos. De ahí resulta que toda la nación trafica igualmente con las colonias y de este tráfico igual resulta que toda la nación en cuerpo se anima a este comercio. La necesidad ha extendido a las islas Canarias el comercio a ciertos puertos de América en cantidad de mil toneladas al año y la misma le ha concedido a los puertos de San Sebastián y Barcelona para las compañías allí establecidas. Las razones que movieron a extender a estos puertos el comercio, obran a favor de todos los puertos de España en los cuales hay aduana para cobrar los derechos de salida y entrada» (RODRÍGUEZ CAMPOMANES, 1988, pp. 36).

Campomanes pretende competir comercialmente con ingleses, franceses, daneses y holandeses. Para ello había que llevar a América los frutos y géneros que los indígenas necesitan, lo que evitaría que colaborasen con los ingleses en la tala de palos de campeche, género muy apreciado para los tintes. Los ingleses llevaban a Honduras harinas y ropas y retornaban con plantas tintóreas que cortaban los nativos o los negros llevados desde Africa y que constituía un buen negocio para los británicos.

Campomanes propone también una mayor comercialización de productos específicos como el tabaco, que requiere muchas precauciones para evitar el contrabando. La producción cubana de tabaco desbordaba el consumo español y debía controlarse su exportación hacia otros países europeos y otras zonas de América Latina donde no había o era de peor calidad. Asimismo, al azúcar lo considera como «un género de indispensable necesidad en España, donde los dulces, confituras, conservas y almívares tienen tanto uso, prescindiendo del que se gasta en el chocolate y otros usos» (RODRÍGUEZ CAMPOMANES, 1988, 
pp. 71). Para garantizar su consumo, cree imprescindible extender la superficie de caña de Cuba y Santo Domingo para poder competir con las producciones portuguesas de Brasil y francesas de Martinica y Guadalupe. Esta medida no era suficiente: había que liberalizar el comercio con Cuba ya que la Compañía de La Habana sólo podía traer dos barcos al año (insuficiente para el consumo español) y los barcos españoles que fuesen desde Cádiz a por azúcar no podían llevar productos a la ida a la isla, lo que duplicaba los costes de transporte. Estas limitaciones perjudicaban a los agricultores cubanos y a los consumidores españoles que compraban azúcar brasileño. El mismo problema existía con el cacao que traía en exclusiva la Compañía de Caracas y que no ascendía ni a la tercera parte de lo cosechado. Estos monopolios perjudicaban a la metrópoli y a las colonias y favorecían el contrabando.

También propone la industrialización, con las menores cargas posibles, para no tener que importar productos que se puedan obtener en España a menor coste, lo que se traduciría en menos gastos por importaciones y pago de impuestos de aduana que encarecen el valor de los géneros y «recaen contra nosotros que somos los consumidores, sin causar más perjuicio a los extranjeros que el de disminuir algo los consumos» (RODRÍGUEZ CAMPOMANES, 1988, pp. 411). Para Campomanes, la producción debe aumentar y diversificarse, lo que satisface las necesidades de los consumidores y hace aumentar la demanda y esta, a su vez, la producción. Si no se vende no se produce y no importa mucho si el consumo se da cerca o lejos a través del comercio. Si falla alguna de las fases (producción, transformación, comercio y consumo) falla todo el ciclo y la economía de una zona.

Estas teorías de Campomanes marcaron la política económica de los ilustrados tanto en la liberalización del comercio interior como el realizado con América: «Una de las más eficaces líneas de actuación del poder consistió en suprimir trabas y anular restricciones. En este plano descuella la promulgación de la libertad de comercio con América. Desde Felipe V, múltiples factores de política internacional y de estructura económica habían ido socavando el sistema de monopolios del tráfico indiano a favor de Sevilla y Cádiz. Ya en 1765 el Gobierno de Madrid dio licencia a diversos puertos para comerciar directamente con las Antillas españolas y las provincias de Campeche, Santa Marta y Río del Hacha. El 2 de febrero de 1778 se extendió la libertad de comercio a Buenos Aires, Chile y Perú. Quedaban ya sentados los fundamentos del memorable reglamento promulgado por Carlos III en 12 de octubre de 1778 para el comercio libre de España con sus Indias» (VOLTES, 1988, pp. 231-232).

Si importante era liberalizar el comercio con América, no lo era menos el crear un mercado nacional, aunque este no llegase hasta finales del siglo XIX. Campomanes, en su «Bosquejo de política económica española», señalaba a mediados del XVIII que este mercado interior dependía en buena medida de lo que él llamaba «surtimiento» que incluía el abastecimiento adecuado de comida, ropa y menaje del hogar (elementos básicos del consumo entonces y ahora) y el alojamiento y hospedaje de caminantes o forasteros con una calidad y precios adaptadas a los medios de cada uno. Campomanes se lamenta del pésimo estado de fondas, mesones, ventas, hosterías, etc., que son muy caras y poco cómodas y apunta que «pide gran atención este surtimiento y mejora de posadas, porque los caminantes consumen mucho caudal y sufren crecidas incomodidades, falta de cama y de comida, muchos mesones, ventas y bodegones que nada más contienen casi que el nombre. Los oficiales del rey, la casa real, los ministros de justicia, los comerciantes, los litigantes, los artífices y todos los demás pasajeros se arruinan con los viajes y se impide la comunicación de los pueblos, que es el modo de hacer florecer el comercio» (RODRÍGUEZ CAMPOMANES, 1984, pp. 180-181). 
Esta demanda de mejores servicios que facilitasen el comercio interior fué otro de los objetivos de los ilustrados hispanos y «es significativo que corresponda a la época de Carlos III el primer plan de caminos reales que implica a todo el territorio y también el propósito de suprimir diversas trabas contra la circulación de bienes. Señalemos como ejemplos el Real Decreto de 19 de noviembre de 1714, que suprimió los «puertos secos», o aduanas interiores, y el de 26 de julio de 1757, que dispuso el libre tránsito de mercancías dentro del país. Por lo demás, estos preceptos no bastan, ni de lejos, para dar por bosquejado un mercado nacional» (VOLTES, 1988, pp. 222).

Por otra parte, las medidas liberalizadoras del mercado interior de 1765, que suprimían las trabas a intermediarios y grandes comerciantes de granos, se eliminan en 1790 volviendo a una libre circulación para «trajineros, cosecheros y dueños de granos que los llevarán a vender a los mercados, así como para los particulares que transportasen el cereal al lugar de su residencia y para su propio consumo» (CASTRO, 1996, pp. 462). Se pretendía con esta medida acabar con los grandes comerciantes que especulaban con un bien escaso y de oferta desigual según las cosechas.

Las relaciones entre producción, comercio y consumo merecieron, asimismo, especial atención por parte de Gaspar Melchor de Jovellanos (1744-1811). En su informe al Consejo Real de Castilla sobre la extracción de aceites a otros reinos, fechado en Sevilla el 14 de mayo de 1774, Jovellanos apunta la clave para el buen funcionamiento económico: un mercado justo basado en «buscar aquella justa proporción que debe haber en los precios del aceite, para que sirva de estimulo al cosechero, sin servir de ruina y desaliento a los consumidores» (JOVELLANOS, 1952, pp. 2). Este producto básico, sólo superado en importancia por el trigo, sólo pervivirá si el cosechero obtiene un precio que le permita recuperar las inversiones y sacar alguna ganancia que le estimule a continuar con su tarea. Si los cultivadores abandonan, los precios se dispararán al alza por la escasa producción. Para Jovellanos, el precio de los productos lo fija la demanda ya que «en los puntos del consumo, todos los frutos tienen un mismo precio, porque el consumo es la medida de su valor. Si se pudiese suponer un fruto sin consumo alguno, este fruto tampoco tendría valor, y por consiguiente no tendría precio (...). En fin, los frutos buscan al consumidor; con que, la regla más segura de esta materia se deberá tomar de los puntos de consumo, que son los que igualan los precios de todos los frutos y la suerte de todos los cosecheros» (JOVELLANOS, 1952, pp. 4).

Esta teoría parece olvidarla en 1780 cuando siendo alcalde de Madrid ordena que se controle el mercado de huevos en la capital (uno de los más importantes en Cuaresma) ubicándolo en la Plaza Mayor y en otras plazas con vigilancia de los «ministros del repeso y repesillos» para evitar los fraudes y posibles problemas de desabastecimiento. También se olvida del libre mercado cuando, en nombre del Ayuntamiento de Gijón, solicita que el consumo de vino y sidra siga sobrecargado con un arbitrio para financiar la instalación de fuentes, empedrado de calles o plantar pinos, alegando que «el consumo de vino es aquí muy escaso, y el de la sidra conviene que tenga alguna sobrecarga, por ser la materia frecuente de la embriaguez de muchos vecinos con perjuicio de sus familias» (JOVELLANOS, 1952, pp. 518) ${ }^{4}$.

Sin embargo, en 1789, Jovellanos vuelve a inclinarse por un mercado libre cuando se refiere a la posible exportación de carbón piedra por el puerto gijonés. La libre extracción y exportación favorecería a numerosas industrias del Principado y del resto de España al reducir los gastos mayores generados por el consumo masivo de leña e incluso ser muy

4 Jovellanos combina en este texto el enfoque económico con el social y moral de las bebidas, ya apuntado por Cadalso. 
competitivo en otros países europeos ya que el principal exportador, Inglaterra, lo vendía mucho más caro por mayores salarios y por la ausencia de competencia (JOVELLANOS, 1952, pp. 464).

En su Discurso a la Real Sociedad de Amigos del País de Asturias sobre los medios de promover la felicidad de aquel Principado (1781), Jovellanos insiste en la importancia del comercio interior y exterior. Para el primero propone que se mejoren las comunicaciones y se establezcan «ferias y mercados donde no los haya y sean convenientes, para que cada concejo y aún cada pueblo, tenga cerca de sí los puntos donde debe vender y consumir sus producciones sobrantes y proveerse de las que necesita, sin la molestia y dispendio de irlas a llevar o traer a muchas leguas de distancia» (JOVELLANOS, 1952, pp. 450). La importancia del comercio exterior la pone de manifiesto en una frase escueta: «el comercio exterior es el que verifica por medio del consumo el valor de las producciones de una provincia». No tiene sentido producir si no hay demanda: «tanto se cultiva y se trabaja cuanto puede venderse y consumirse».

En sus instrucciones a la Junta de Estado que creó el 8 de julio de 1787, el conde de Floridablanca les encomienda que potencien el tráfico interior y exterior, los canales de riego y de navegación y el libre comercio de granos: «encargo a la Junta procure sostener con tesón la pragmática del libre comercio de granos, el destierro de las tasas y la libertad o minoración de gabelas y gravámenes en la circulación de los frutos e industria de mis vasallos» (FLORIDABLANCA, 1867, pp. 224) porque se ha de procurar que «toda manufactura nacional circule dentro del reino y salga de él sin que se cobre derecho alguno por su tráfico, venta o extracción. Cuando este pensamiento pueda ponerse en práctica, se logrará la extensión y perfección de las fábricas, el aumento de población, y el empleo y manutención de más de la mitad de los vasallos» (FLORIDABLANCA, 1867, pp. 225).

El conde de Floridablanca señala que es muy buena la idea de una contribución única proporcional a la riqueza de cada súbdito pero que es muy difícil su aplicación y «no hay nación, de las más activas e iluminadas, que haya establecido ni cobre sus tributos por este medio de contribución única, en el sentido que la toman los especuladores franceses, ingleses, holandeses; y todos los estados de la Europa se han visto obligados a dividir, clasificar y multiplicar los tributos internos, gravando todas las especies de consumo ordinario y otras que pertenecen al lujo, para exigir completa la cuota de las contribuciones precisas para las obligaciones del Estado, facilitar y suavizar su exacción» (FLORIDABLANCA, 1867, pp. 254).

En este enfoque económico hay que incluir también las aportaciones de Álvaro Florez Estrada (1766-1853) quien en «Curso de Economía Política ${ }^{5}$ divide la riqueza en tres categorías: productiva (reinvirtiéndola), de consumo (para satisfacer nuestras necesidades inmediatas y caprichos) y la estacionaria (masa del producto anual sobrante no empleada en el consumo ni reinvertida para mejorar la producción), aunque «no hay especie de riqueza que no se consuma, pero hay una que se consume reproduciéndose, y otra que se consume sin reproducirse» (FLOREZ ESTRADA, 1958, pp. 38).

Florez Estrada rechaza la teoría de Malthus de que hay algunos países con disposición a no consumir: «Jamás hubo en la clase trabajadora falta de voluntad para consumir los artículos que otras clases de la misma sociedad consideran como necesarios, útiles o agradables. Si para lograr estos artículos y los de mayor lujo bastara la sola voluntad, no habría mendigo que no consumiese tanto como el hombre más rico ni el mercado se hallaría jamás con productos sobrantes. Todos deseamos gozar, y, para conseguirlo, no se

5 Publicado por primera vez durante su exilio londinense en 1828, es el primer tratado de economía escrito en español (MARTÍNEZ CACHERO, 1976, pp. 112). 
necesita otra cosa más que hacer compras. La imposibilidad, pues, de ofrecer un equivalente por los artículos que se desean, es la única causa que tiene a tantos hombres en estado de penuria (...). La falta de pedidos dimana de una de dos causas, o del precio naturalmente alto de los productos, o de las restricciones puestas a su introducción en los países extranjeros (...). Alguna vez habrá superabundancia de un artículo, pero de todos nunca la puede haber. Por más industriosa que llegue a ser, jamás una nación producirá artículos que no pueda consumir (...). Es tal la circulación de las mercancías baratas y de buena calidad que, sin embargo, de cuantas leyes restrictivas se inventen y de cuantos resguardos se formen a fin de alejarlas, se introducirán y suplantarán las mercancías nacionales si son más costosas y de peor calidad» (FLOREZ ESTRADA, 1958, pp. 63-65). En el aumento productivo y en la bajada de precios jugaría, según Florez Estrada, un papel decisivo la mecanización industrial, tema apenas apuntado por otros ilustrados en décadas anteriores.

La parte cuarta del «Curso de Economía Política» la dedica Florez Estrada exclusivamente al consumo, tras analizar en las anteriores la producción, distribución y cambios de la riqueza, a las que considera medios para lograr el objetivo de consumir. El consumo lo define como «la destrucción de las cualidades que hacen útiles y apreciables los productos». Para Florez Estrada, lo que no puede perder valor no es consumible y los artículos que carecen de valor no deben ser considerados como objeto de consumo. Este se mediría por el valor y no por el volumen, peso o cantidad. También diferencia el que satisface necesidades inmediatas y el superfluo, el productivo del improductivo, el público del privado, etc.

Florez Estrada hace hincapié en la importancia del consumo productivo (capital que se invierte en pagar salarios, construir máquinas o comprar materias manufacturables) ya que nunca deben computarse como gastos malogrados al reembolsarse posteriormente y como «cuanto más considerables sean los consumos productivos, tanto mayor será la producción de la riqueza, es necesario, a fin de que la industria prospere». Este consumo productivo debe ir acompañado del improductivo ya que «aunque todo consumo improductivo, por lo que mira al aumento de la riqueza, deba considerarse como del todo perdido, sin embargo es de la mayor importancia cuando contribuye a satisfacer nuestras verdaderas necesidades. Sólo es inútil cuando no satisface necesidad alguna, o cuando bajo ningún aspecto proporciona comodidad física ni moral. Si el hombre no hiciera otros consumos más que los productivos, se fatigaría en vano; no obtendría el menor goce; no podría conservar su existencia, y si sus consumos improductivos son mezquinos e insuficientes pasará una vida miserable. Para que goce y sea útil a sus amigos y a la humanidad, es absolutamente necesario que efectúe consumos improductivos; sin ellos no satisfaría tamañas necesidades, y sus fatigas no tendrían objeto alguno racional» (FLOREZ ESTRADA, 1958, pp. 256).

Florez Estrada critica que el lujo haga avanzar la producción y el empleo y señala que sólo hace aumentar las desigualdades y «con sólo desterrar de un país el lujo y su compañera inseparable la ociosidad, medran rápidamente la industria y el capital», dedicándose a la producción de artículos necesarios que son los que contribuyen «a la conservación de la vida, de la salud y de las comodidades habituales de las varias clases de consumidores». Florez Estrada hace también hincapié en la importancia del consumo público (a diferencia de Adam Smith y Stuart Mill lo considera productivo), efectuado por el gobierno, que «es el gran consumidor» para subvenir los gastos del Estado en servicios comunitarios: la recaudación estatal debe ser elevada para hacer frente con desahogo a las muchas demandas de la sociedad.

José de Canga Argüelles (1770-1842) publica en 1826 su obra fundamental (Diccionario de Hacienda con aplicación a España), en la que hace numerosas referencias al consumo. Sobre este tema, además de en la voz consumo, ofrece datos en otras muchas como 
accisa, contrabando, contribuciones, etc. Se centra en el consumo de artículos básicos como el pan, lo cual es bastante lógico si se tiene en cuenta que cifra los gastos alimenticios de los españoles en un $40 \%$ de los totales y los del pan en el $40 \%$ de los de alimentación.

Canga Argüelles, siguiendo a Arnould, apunta que existían tres medios para calcular el consumo de cada individuo: la ración del soldado (incide en que el hombre consume más que la mujer y ésta más que los niños), los asientos o registros de las localidades que tienen abastos cerrados, y/o la división de las cosechas anuales (tras quitar la sexta parte para simiente del año siguiente) entre el número de habitantes. También señala que las contribuciones sobre los consumos están muy generalizadas en todos los países, disintiendo de Arnould cuando éste afirmaba que es la contribución más justa al recaer sobre toda la sociedad proporcionalmente a la riqueza. Canga Argüelles señala que, en España, afecta más a las familias pobres por tener más hijos y ver grabado su consumo básico, inclinándose por su supresión aunque «entiendo que los Gobiernos deben examinar con cuidado el giro de las opiniones y de las costumbres del pueblo y mirarse mucho antes de decidirse a abolir las contribuciones sobre los consumos, una vez establecidas» (CANGA ARGÜELLES, 1968, pp. 377).

\section{Enfoque geográfico del consumo}

Aunque en los apartados anteriores veíamos que casi todos los autores hacían alusiones espaciales sobre el consumo (origen parisino de los cambios en las modas, comercio con América, etc.) son Cadalso y Canga Argüelles los que mayores aportaciones ofrecen en este aspecto.

En varias de sus «Cartas Marruecas», José Cadalso apunta las diferencias en el consumo entre distintas zonas de España. En la XXI, refiriéndose a Madrid señala que «la multitud y variedad de trajes, costumbres, lenguas y usos, es igual (que) en todas las cortes por el concurso de extranjeros que acude a ellas; pero las provincias interiores de España, que por su poco comercio, malos caminos y ninguna diversión, no tienen igual concurrencia, producen hoy unos hombres compuestos de los mismos vicios y virtudes que sus quintos abuelos» (CADALSO, 1992, pp. 53). Las diferencias ante el consumo aparecen muy claras: «Por cada petimetre que se vea mudar de moda siempre que se lo manda su peluquero o sastre, habrá cien mil españoles que no han reformado un ápice en su traje antiguo» (CADALSO, 1992, pp. 54). En la XXVI señala que los catalanes son los más industriosos de España, estando a mil leguas de gallegos, andaluces y castellanos hasta el punto de que algunos los llaman los holandeses de España. Para Cadalso, Cataluña «florecerá mientras no se introduzca en ella el lujo personal y la manía de ennoblecerse los artesanos: dos vicios que se oponen al genio que hasta ahora les ha enriquecido» (CADALSO, 1992, pp. 63-64).

Por su parte, Canga Argüelles recupera una memoria de 1787 de Pedro Lerena que revisa los datos del consumo de los principales productos en España. En granos y semillas el consumo superaba a la cosecha y era necesario importarlos de Italia, Francia y Holanda. También había déficit de ganado vacuno y porcino que se importaban de Irlanda y Francia. Había superavit de vinos y licores y una producción semejante a la demanda de ganado lanar.

Manejando datos del Ministerio de Hacienda de 1802, Canga Argüelles nos facilita una visión espacial según la división existente entonces de España en 34 provincias, sugerente ya que nos permite conocer los déficit y excedentes de cada una de ellas ${ }^{6}$.

6 No menciona datos de Canarias, Cádiz ni Santander mientras los de Baleares los desglosa entre Mallorca e Ibiza sin explicar las razones. 
En la España Atlántica había un considerable déficit de granos: Galicia, Asturias y Vizcaya consumían el doble de lo producido. Galicia exportaba vino y ganado, lienzos finos, paños bastos y sombreros. Asturias importaba dos tercios del vino y licores consumidos y cantidades considerables de lino y cáñamo mientras vendía los excedentes de ganados, habas, avellanas, carbón de piedra, cobre, armas de fuego y loza. Vizcaya tenía excedentes de hierro en barras y labrado, cobre manufacturado, clavazón y herrajes. Guipúzcoa también exportaba manufacturas de hierro y cobre labrado e importaba granos, legumbres, vino y lino, mientras Alava exportaba un $10 \%$ de los granos que producía.

Navarra se autoabastecía en aceite, ganado, lienzos y paños, tenía sobrantes de trigo, lana, corderos y dos tercios del hierro que se labraba en sus ingenios.

A Aragón le sobraban granos, apenas se abastecía de manufacturas de lana y seda pero le sobraban los paños que abastecían al ejército. Cataluña tenía un déficit enorme de granos, importaba carne y le sobraba mucho vino. También importaba lanas, algodones y seda para su transformación y posterior venta: «la inmensa extensión de sus fábricas e industria rendía una cantidad de dos tercios mayor en géneros de los que necesitaban los habitantes, modelo de laboriosidad y de amor al trabajo» (CANGA ARGÜELLES, 1968, pp. 373).

En la actual Castilla-León, Ávila tenía superavit de trigo, cebada, garbanzos, ganados, lanas y paños. Salamanca también producía más granos, lino, lana, ganados, curtidos, paños y loza de los consumidos mientras importaba vino y aceite. Zamora tenía excedentes de cereales, garbanzos, judías, vino, zumaque, lana y loza, y Toro exportaba granos, garbanzos y carbón. Palencia vendía granos, vino, mantas, bayetas y estameñas. Burgos exportaba vino, lana, productos de seda y paños y compraba granos. Valladolid tenía excedentes considerables de granos, vino, ganado lanar y manufacturas de lana e importaba bastante aceite. A Segovia le sobraban cereales, vino, lana, paños y papel y le faltaba aceite. Por último, Soria tenía déficit de vino y aceite y grandes excedentes de granos y más reducidos de lonas, paños, carneros y lana fina.

En la meseta sur, Madrid era claramente deficitario: «ni de granos, ni de vino, licores y legumbres tenía esta provincia lo suficiente para el consumo, y los productos de sus manufacturas eran de corta entidad comparados con los que reclamaban las necesidades de sus moradores» (CANGA ARGÜELLES, 1968, pp. 374).

A Guadalajara le faltaban aceite, lino, lana y cáñamo para el surtido de sus habitantes y le sobraban granos, legumbres, vinos y ganado. Cuenca tenía excedentes de granos, vino, lana, hierro y ganado y le faltaban legumbres. Toledo exportaba granos, legumbres, aceite, esparto, jabón, paños, vidrio y papel, y La Mancha granos, vino, ganado, azafrán, sosa y seda. Extremadura tenía déficit de granos, vino, lino y cáñamo y superavit de aceite, ganados y paños.

En Andalucía, Jaén importaba granos y vendía curtidos; Córdoba importaba casi la mitad de los cereales consumidos y vendía aceite, ganado, jabón, manufacturas de seda, hilos curtidos y obras de platería. Sevilla tenía sobrantes de vino y aceite y exportaba tejidos de seda y loza a América. A Granada le faltaban granos y le sobraban vinos, aceites y muchas manufacturas.

En Murcia escaseaban los granos y legumbres para el abasto propio y producía mucha sosa, barrilla, seda, cáñamo y loza para exportar. En el «feracísimo reino» de Valencia faltaban la mitad del trigo, garbanzos y ganados y le sobraban arroces, aceite, vino, seda fina, cáñamo, lienzos, paños, papel, jabón, loza y vidrio. Por último, en Baleares faltaba trigo en Mallorca e Ibiza, Mallorca tenía déficit de ganado e Ibiza de aceite. Ambas tenían excedentes de almendras, naranjas y limones. 


\section{Bibliografía}

ALONSO, L.E. y CONDE, F. (1994): Historia del consumo en España: una aproximación a sus orígenes y primer desarrollo, Madrid, Debate, $254 \mathrm{p}$.

ARGEMI D’ABADAL, L. (1988): Agricultura e Ilustración. Antología del pensamiento agrario ilustrado, Madrid, MAPA.

CADALSO, J. (1992): Cartas marruecas, Barcelona, Planeta, 220 p.

CANGA ARGÜELlES, J. (1968): Diccionario de Hacienda, Madrid, BAE, t. 1, 593 p.

CASTRO, C. de (1996): Campomanes. Estado y reformismo ilustrado, Madrid, Alianza, 540 p.

ENRÍQUEZ FERNÁNDEZ, J.C. (1994a): «El pensamiento social agrario durante la Ilustración Vasca» en Pensamiento agrario vasco. Mitos y realidades, Bilbao, Univ. País Vasco, 401 p., cfr. pp. 11-13.

ENRİQUEZ FERNÁNDEZ, J.C. (1994b): «El problema de la tierra en la crisis del sistema foral vasco. Sus modelos de resolución. Los expedientes fisiócratas, ilustrados y burgueses (renta, trabajo y mercancía)» en Pensamiento agrario vasco. Mitos y realidades, Bilbao, Univ. País Vasco, 401 p., cfr. pp. 15-70.

FEIJOO, B.J. (1952): Obras escogidas, Madrid, BAE, 609 p.

FLOREZ ESTRADA, A. (1958): Obras, Madrid, BAE, t. I, 409 p.

FLORIDABLANCA, Conde de (1867): Obras originales, Madrid, BAE, 532 p.

JOVELLANOS, G.M. (1952): Obras, Madrid, BAE, t. 2, 548 p.

MARTÍNEZ CACHERO, L.A. (1976): Economistas y hacendistas asturianos, Salinas, Ayalga, $190 \mathrm{p}$.

MESTRE SANCHIS, A. (1993): La Ilustración, Madrid, Síntesis, 203 p.

NEGRIN, O. (1984): Ilustración y educación. La Sociedad Económica Matritense, Madrid, Nacional, $190 \mathrm{p}$.

RODRÍGUEZ CAMPOMANES, P. (1978): Discurso sobre la educación popular de los artesanos y su fomento, Madrid, Ed. Nacional, $271 \mathrm{p}$.

RODRÍGUEZ CAMPOMANES, P. (1984): Bosquejo de política económica española, Madrid, Editora Nacional, $182 \mathrm{p}$.

RODRÍGUEZ CAMPOMANES, P. (1988): Reflexiones sobre el comercio español a Indias (1762), Madrid, Inst. Estudios Fiscales, 458 p.

VOLTES, P. (1988): «La política económica» en Historia de España, Madrid, Espasa Calpe, t. 31, pp. 213-245. 